Journal of librarianship and information science, 29 (1), March 1997, 3-7. [ISSN 0961-0006] [online]: http://lis.sagepub.com/cgi/reprint/29/1/3 [Accessed 20 March 2005] ; and reprinted, by permission, in Education for Information, 16 (1), March 1998, 1-8. [ISSN 0167-8329] )

\title{
PEERING INTO THE MIST AND STRUGGLING THROUGH IT - THE EDUCATION AND TRAINING OF THE FUTURE INFORMATION PROFESSIONAL
}

\author{
Ian M. Johnson
}

Head, School of Information and Media, The Robert Gordon University, Aberdeen

A recent guest editorial comment in 'Education for Information' challenged its readers to ask themselves whether they were producing students with up to date and relevant knowledge and skills (1). Read over lunch in the office during what is laughably described as the Summer Vacation, it provoked an immediate reaction. Clearly, however, the response is one which needs to be addressed, not to the educators, but to practitioners. Hence its appearance in this journal, perhaps a fitting conclusion to my five year term on its Editorial Board.

What I am not going to try to do is to discuss some of the changes affecting the profession. Everyone is well aware of the changes in the place of information in society; in the availability and sophistication of information technology; indeed, in the nature of the information and communication industry; and the added complexities these have brought to the task of maintaining and developing information services.

What I would like to do is to outline some of the responses to these changes which are being made by the Schools of Information and Library Studies, particularly the Schools which I know best, in terms of:

- how we have been updating our curricula and courses to develop the technical competencies which are changing rapidly and increasingly important

- what we are doing or what we are about to do to meet the growing need for management and leadership skills

- what we still need to do,

- and how practitioners will have to help us if they expect us to produce the kind of professional they would like to employ. 
The changes which are taking place are not new, although they have been gathering pace over the last few years. They have certainly not gone unnoticed in the Schools of Information and Library Studies. However, it is fair to say that much of our response, in terms of curricular revision, takes place without attracting much outside attention. Although we generally consult widely when we make these changes, I suspect that the profession at large usually becomes aware of changes only when the name of the course, or the School, changes to reflect a cumulated shift of emphasis, a growing diversity in the portfolio of courses, or some form of collaboration with other disciplines. This happened during the 1980s when many Schools changed their course titles from 'Librarianship' to 'Librarianship and Information Studies'. During the 1990s, the trend has been to shift the emphasis further to 'Information and Library Studies', or to remove any mention of librarianship, but even the title of a course and its subsidiary elements does not necessarily convey the changes which have been made. For example, we recently had to demonstrate the emphasis on computing in our Bachelors degree in Information and Library Studies to secure improved funding; the title does little to explain that nearly $60 \%$ is focused on computer applications.

In our rapidly changing world, change has to be a managed activity. In the Schools, we not only expect that the syllabi of course units will be revised by their tutors to take account of the latest developments - we also monitor this process through well established annual review processes, focused on both curricular content and the related staff development needs. In addition, every 5 years there is a major review, usually involving one or more of the professional associations, as they accredit our courses for a fixed period. As well as these rigorous processes, the pace of change - in the education system as well as in the discipline - has been such that most Information and Library Studies courses have gone through major structural revisions in recent years - in my University, three times in the past seven years, and that is usually accompanied by further reconsideration of the syllabi.

What we have been trying to do, within some severe constraints on our resources, is not only to reflect the changes taking place in the profession's knowledge base, but also to keep in step with changes in the job market. It was, of course, the case that the demand for many of the specialists needed in the emerging sectors of the job market was, initially, so small that a separate course could not be viable, and we had to attempt to cater for them within a generalist programme. Inevitably a single programme which tries to prepare students for a variety of employment opportunities fails to satisfy some students or prospective employers. That perhaps explains some of the criticism the Schools have faced in recent years, as the pace of change has accelerated. It is, however, interesting 
to note that the Schools, are now, in Britain at least, growing more confident of the size of certain specialist sectors of the job market, and they are beginning to introduce additional programmes of study to run alongside their established programmes. The University of Northumbria at Newcastle has, for example, recently identified the growing demand from public and private sector organisations for specialists to manage their corporate records as the focus of a new Masters degree programme.

There is also a growing appreciation that we now have so much vital information that we need to be able to store and retrieve it more efficiently. We are beginning to appreciate the consequences of having the ability to retrieve more information than can be easily used, partly as a result of a multiplicity of information systems which largely duplicate the coverage of others, and partly because of retrieval systems which lack the necessary specificity to pinpoint only the information we need. Consequently, more attention is being given to teaching not only the skills needed to find information, but also the skills needed to evaluate, consolidate and repackage what we find into a more usable form. This repackaging of information adds value to the information, and has created many new - and well paid - jobs for professional researchers and information analysts. It also led - 4 or 5 years ago - to the introduction of specialist courses in Information Analysis by, for example, the Prague University of Economics, and The Robert Gordon University.

We are also well aware that other changes are taking place, reflecting the growing significance of computing and telecommunications for libraries and information services and the growing job market for specialists with expertise in these areas. Recently, about $15 \%$ of the adverts for jobs in libraries and information services in Britain have called for a high level of knowledge of this area as a prerequisite. From 1997, we shall see at least two of the British Schools offering Masters degree programmes in this area, The Robert Gordon University and Sheffield University. In Aberdeen, the programme in Electronic Information Management will have substantial inputs from two Schools, Electronic Engineering and Computer Science, and has a strong focus on hardware. The Sheffield programme in information Systems will also be the result of collaboration with the University's Department of Computer Science.

The kind of developments I have just outlined are clearly changing the role which the Schools can play in the information industry. Other occupational groups within the industry are being as profoundly affected by these changes as the information service professional, and it has been apparent for some years that - on an individual basis - many of the industry's employees have a limited perspective on the industry and a narrow knowledge and skills base. But, if we 
take a strategic view of the workforce across the whole of the information and communication industry, it is evident that the people who work in it could and should share a common base of knowledge and skills, although their specialist expertise - and their aims and attitudes - do differ. It is to provide a broader base of knowledge, to develop versatile and resourceful practitioners, that new programmes, aimed at alternative employment sectors in the information and communication industry, are beginning to be developed in what were once Schools of Librarianship.

For example, programmes in Publishing Studies have been started by three of the British 'Library Schools'. There are similar developments taking place elsewhere in Europe, for example in our partner institutions in Amsterdam and Leipzig, where the institutional management has recognised the similarities and potential for synergistic growth, and has placed publishing studies in the same Faculty or School as librarianship and information science.

The recognition that information is a major asset, a major resource, or at least a major expense, has compelled many organisations to look at the way in which they manage their information systems and services. The increasing tendency in industrial and commercial organisations, in government departments, in hospitals, and in universities - for their computer systems, telecommunications, archival and filing systems, libraries and information services to be managed as a single unit - is leading to a growing demand for 'information managers'. In a climate of cost-cutting and down-sizing, competition for these jobs from highly qualified technical and communications professionals appears to be growing. In reality we have little to fear from the competition at present. A recent study which we undertook in the oil industry revealed that at present there appear to be three kinds of managers in that industry:

- the IT managers, who understand the technology but who know little about information and its uses

- the specialist managers, who know a little about information sources in their field, but little about IT

and

- the librarians, who have an understanding of IT and are fully familiar with information needs and sources (2).

This is probably fairly typical. Other studies have confirmed that general managers in industry know little about information management or information technology, and need our advice, not only on technical issues, but also on the legal, ethical and financial issues which have been raised by the spread of electronic information systems. Unfortunately information specialists tend to 
focus on the routine tasks required to maintain their serve, but, if we wish to become part of management at a strategic level, we need to develop the skills to operate effectively at that level.

For some years, the Schools in Strathclyde and Sheffield have contributed relevant course units within their Universities' MBA programmes, and more recently Loughborough University has initiated an MBA programme in Information Management. In collaboration with colleagues in Copenhagen and the Netherlands, we are planning an International Masters degree in Corporate Information Strategy, to be offered on a distance learning basis, possibly commencing in 1998.

Of course, success at the highest levels of management is not necessarily based solely on understanding and applying the principles of management, or on being a skilled researcher. We need to produce more people with leadership qualities, professionals who can not only convince corporate management's that information services are essential activities, and that their efforts make a significant contribution to the achievement of the corporate objectives, but also raise their sights and persuade governments that information provision should be a major policy area.

You may ask 'what can Schools of Librarianship and Information Studies do about this?' This is a question which we are increasingly asking ourselves. Is it sufficient to ensure that our curriculum informs the students about the benefits of modern information systems? Do we do enough to help them begin to understand organisational politics? 'How can we develop information professionals who can attract the interest of politicians and other decision makers, and effectively argue the case for increased support for information services?' Should we give more attention to developing students' interpersonal skills, to making oral presentations, and to team-working and leadership?

The honest answer is that we probably have not given enough attention to those qualities until recently. We can only speculate as to the reason for that oversight, but it was perhaps because so many of our students, in the past, took jobs in large library systems in which the responsibility for promoting the library's interests rested on a small number of senior staff - people who had probably reached their senior position because they possessed the necessary skills. In the last twenty years, an increasing proportion (now more than 50\%) of our students have left to work in small specialist libraries and information centres, often in situations where they are the only professional, and where their employers' expect them to be able to work more independently. Clearly they need not only professional skills, but also appropriate personal qualities. Some 
of the Schools of Librarianship and Information Studies have begun to revise their teaching methods to try to enhance skills such as project management, encouraged by the 'Enterprise in Higher Education Initiative' which the government sponsored a few years ago.

Because of the nature of the higher education institutions in which librarianship has developed in Britain (and many other countries), and because, at entry level, information work is a very practical discipline, the emphasis in the Schools has been largely on teaching and on developing technical competencies, rather than on developing students' ability to learn. In the rapidly changing environment in which we now work, the ability to continually learn is essential. As Tom Peters has said, "The only job security lies in being more talented tomorrow than you are today". Where we can, in Britain, we are changing our approaches to teaching and learning, but there are some countries where state regulations make this difficult. If we want the next generation of professionals to be more flexible and versatile, the professional bodies (and their individual members) will need to lobby hard for changes in the education system. They may need to lobby the Schools to change, but they will also have to lobby governments to permit and support the change.

Another area in which many Schools are not developing as much as they might wish, or as much as is necessary for the benefit of the profession, is in research activity. Higher education cannot be up to date and stimulating unless the staff are undertaking research, and I do not believe that we can produce young people with the qualities required to lead the profession in a more challenging future unless the best of them can be given the opportunity to be intellectually stretched through involvement in research. A handicap faced by many Schools in Europe is that they are not in Universities where staff are required to do research. Moreover, government funding for research projects and research studentships in our field appear to be contracting everywhere in Europe. Clearly, if we believe that research is vital to the future of our profession, then we need to ask how we can help to develop it? It seems that the current fashion is for 'research' funding to be assigned to 'development' and for it to be carried out by libraries and information services rather than by the institutions concerned with teaching and research; but if teachers are not involved in these processes, how can it be expected that their students will be excited about new practices? As individual institutions, the Schools would welcome being invited to become more involved in libraries own Research and Development activities, but collectively we also need support to lobby managements and the politicians much more to secure more adequate support for $R \& D$ in this field. 
Practical experience before or during the course of their studies can also help students develop vital skills and a professional outlook. The students themselves rate this experience highly as a way of integrating theory with practice, and of learning to recognise the challenges likely to be encountered in developing a service. Despite the fact that employers always tell us that they place a high value on practical experience when recruiting staff, there appears to be a reluctance in some organisations to offering work experience to students. So what do we need to do to persuade more organisations that to arrange challenging programmes to provide a range of experience for students, and perhaps to pay them a small salary for the duration, would be a worthwhile investment? Industrial placements bring many benefits to the employer in addition to an opportunity for the evaluation of possible future employees: enthusiastic young professionals with a wide spectrum of skills who can adapt quickly and help introduce the latest ideas into the organisation.

There are, of course, other ways of transferring experiences and insights to students. Could we bring practitioners into the Schools, not only as visiting lecturers for an hour or so, but on a long term basis, say for a year or three years?

They might ask what their staff could gain from this. One of my staff left to take up a senior position with a major publishing group. He had only been with us for little over a year, after he joined us to get away from a job in industry which had not turned out to be what he expected. Just before he left, after the head-hunters had caught up with him, he explained why he felt it had been a very useful developmental experience. He focused on three points. Although he had had good presentation skills before he was appointed (he wouldn't have got the job if he hadn't), he had been accustomed to working with a script. After a relatively short period teaching, he was able to speak in an organised and effective way for up to an hour with relatively few notes. Secondly, most of his previous jobs had focused his attention rather narrowly, and we had required him to take an all round view of the subject area. Finally, he commented that, in industry he had largely been expected to focus on short term objectives, but we expected him to think about the long term as well. He believed that these would all be valuable characteristics in the position to which he was going, one in which he was to be a senior product manager, developing a key area of a major international group's future business. He had become a 'reflective practitioner'.

We all face problems in providing cover for staff who are away for any length of time. Perhaps long term exchanges would be a way of both Universities and industry benefiting? Or perhaps another alternative might be for a commercial 
organisation to sponsor a post in a School, to provide a position for a senior practitioner to apply his or her experience to teaching, research and consultancy.

I would not try to deny that some of the suggestions I have made would be difficult to put into practice, but I do believe that we need to make the effort.

One of my major interests lies in the improvement of professional education in the developing countries, so I tend to watch what is happening in those countries as well as what is happening in Europe, just as economists do. The economists keep telling us that all the European countries are facing a major challenge from the so called 'Tiger economies' particularly the developing countries of the Pacific Rim. I think most European members of the information professions would find it interesting, and possibly as disturbing as I do, to compare their investment in information services and related professional education with what is happening in Europe.

Some may have heard of 'Singapore 2000' and the plan for an 'Intelligent island', heavily dependent on IT. The level of investment in equipment and personnel in their Universities may not be so familiar, but it is the envy of most Universities in Western Europe. In Malaysia, a similar approach is being taken. Manpower development lies at the heart of the 'Malaysia 2000' plan, aimed at raising local personnel quickly to the leading edge of professional knowledge in our field just as much as in others. Within a few years, the skills base of the Singaporean and Malaysian institutions threatens to be more relevant to future needs than that of most European Schools of Information and Library Studies.

Why should this be the case? In Europe, information services still appear undervalued by governments and corporations. Equally, education for information management, and education in information use, rarely feature explicitly in national government or European Commission priorities, yet without effective management of our information resources, so many other economic objectives will not be realised. If we believe that information is the lifeblood of a developed economy, can we be satisfied that what we are doing is sufficient to maintain or improve the future health of the economies of the countries we work in?

I believe that the Schools of Information and Library Studies in Europe do have a fairly clear vision of the future. We can see a lot of what is required by information services to help European industry to be competitive; we are taking a pragmatic approach to preparing the people needed now; and we can see how we can develop a new generation of professionals with the necessary technical knowledge. If we are to succeed in the struggle to develop the skills and 
attitudes which information management also requires, we cannot be satisfied with what we are doing. But to prepare a new generation of professionals, we need the support of practitioners and of the commercial companies supplying the information world.

Let me be the first to acknowledge that the Schools already enjoy some very generous support from commercial organisations in the information industry. For example, Knight Ridder gives all Schools of Information and Library Studies free access to DIALOG and DATASTAR for teaching purposes. My own students use about $\$ 1,000$ of time on DIALOG each month, which we could not otherwise afford, and without which they would be less able to meet their prospective employers' expectations. Other companies have made gifts of library automation packages and compact discs. We now have more than 80 compact discs. If we had had to pay for all our CDs, we would have had fewer than ten. The ready availability of these systems has led to an improved understanding of the strengths and weaknesses of the various formats and retrieval systems, and much greater confidence among students in the use of electronic media.

Support such as this and the work experience provided for our students has been invaluable, but if, as a profession, we wish to have a greater influence on our own future and a more significant role in the Information Society, we need to work together even more closely and more effectively than we appear to have done in the recent past in sharing experience and lobbying the decision makers so that we can produce a generation of professional leaders who are not only technologically competent, but who can also manage in a fast moving environment, and who can make information services more visible and more highly regarded.

\section{REFERENCES}

1. MAHON, Barry. Editorial. Education for Information, 14 (2), 1996, 83-84

2. SMITH, J.M. and others. The 'Intelligent City': electronic information and its potential in the provision of health and safety information in the oil and gas industry. 1996. The Robert Gordon University. (British Library R\&D Report 6255)

A version of this paper was presented to the annual conference of EUSIDIC: the European Association of Information Services, Bologna, October 1996. 
